\title{
Da Luz à Mesa: o Ano Internacional da Agricultura Familiar na Escola
}

\section{From Light to Meal: the International Year of Family Farming at School}

\author{
${ }^{1}$ Luciana Maria de Jesus Baptista Gomes \\ ${ }^{2}$ Sônia Maria da Silva Oliveira
}

\section{RESUMO}

\begin{abstract}
A Agricultura Familiar é responsável por 70\% dos produtos agropecuários que abastecem a mesa do brasileiro. Segundo a Organização das Nações Unidas para Alimentação e Agricultura, a agricultura familiar e de pequena escala estão vinculados à segurança alimentar mundial, preserva os alimentos tradicionais, além de contribuir para a qualidade da alimentação, proteção da agrobiodiversidade e o uso sustentável dos recursos naturais. Assim, dada a sua relevância, foi estabelecido 2014 como o Ano Internacional da Agricultura Familiar. Reconhecendo este impacto, o presente trabalho é uma descrição de uma estratégia de valorização da Agricultura Familiar na escola, por meio da Metodologia de Projeto, desenvolvido interdisciplinarmente, numa perspectiva dialógica, com promoção da aprendizagem por meio da interação social. Como resultado, foi observado o envolvimento progressivo do aluno durante o percurso do projeto, com o desenvolvimento tanto cognitivo e social.
\end{abstract}

Palavras-chave: Agricultura familiar; metodologia de projetos.

\section{ABSTRACT:}

The Family Agriculture accounts for $70 \%$ of agricultural products that cater to the Brazilian table. According to the Food and Agriculture Organization of United Nation, family farming and small scale are linked to global food security, preserving traditional foods, as well as contribute to the quality of food, protection of agricultural biodiversity and sustainable use of natural resources. Thus, given its importance, it was established in 2014 as the International Year of Family Farming. Acknowledging this impact, this paper is a description of a Family Farming recovery strategy in school, through the design methodology, developed interdisciplinary, a dialogical perspective, promoting learning through social interaction. As a result, we observed the progressive student involvement during the design of the course, with both cognitive and social development.

Keywords: Family farming; design methodology. 


\section{INTRODUÇÃO}

A Agricultura Familiar é aquela em que o cultivo de terra é realizado por pequenos proprietários rurais, tendo como mão-de-obra principalmente a família e alguns poucos trabalhadores assalariados. Segundo a Organização das Nações Unidas para Alimentação e Agricultura (FAO, 2014), a agricultura familiar e de pequena escala estão vinculadas à segurança alimentar mundial, preserva os alimentos tradicionais, além de contribuir para a qualidade da alimentação, proteção da agrobiodiversidade e o uso sustentável dos recursos naturais.

Assim, dada a sua relevância, foi estabelecido 2014 como o Ano Internacional da Agricultura Familiar, com um dos objetivos "aumentar o conhecimento, a comunicação e a conscientização pública" (FAO, op.cit., 2014) deste setor econômico, aumentando, dessa forma, a visibilidade da agricultura familiar e dos pequenos agricultores.

Porém, ao mesmo tempo que se reconhece a importância da agricultura familiar na para a riqueza do País - é representativa e não perdeu sua força nos últimos anos representando 10\% do PIB nacional (GUILHOTO et. al., 2007) - há um desconhecimento do público em geral sobre a fonte da produção dos alimentos agropecuários que abastecem a mesa do brasileiro e, no caso regional, a mesa da pessoa que mora no estado do Rio de Janeiro - pesquisas demonstram que $70 \%$ de tudo que está no cardápio é oriundo da Agricultura Familiar, que ainda apresenta expectativa de crescimento para as próximas décadas (SPAROVEK et al., 2013).

Dada esta realidade contraditória, houve a necessidade de informar e discutir com os alunos sobre a Agricultura Familiar, aproveitando os conteúdos de diferentes componentes curriculares da Educação Básica. Isso significa dizer sobre o professor agindo com intencionalidade pedagógica, ou seja, "em função de objetivos previamente definidos" (SAVIANI, 2007, p.60) para criação de oportunidades de aprendizagem efetiva do assunto por parte do aluno.

Para a apresentação e discussão em sala de aula, as atividades pedagógicas foram desenvolvidas à luz de Vygotsky (2007, p.164), que vê "o aprendizado como um processo profundamente social, enfatiza o diálogo e as diversas funções da linguagem na instrução e no desenvolvimento cognitivo”, e de Paulo Freire (1997, p.38) para o qual "a tarefa coerente do educador é (...) desafiar o educando com quem se comunica, a quem comunica, produzir sua compreensão do que vem sendo comunicado”.

Assim, valoriza-se a postura dialógico entre professor e aluno, tornando a aula dinâmica e motivacional, com a contribuição dos alunos com suas posições e concepções prévias, que são elaboradas a partir da vivência dos alunos com o mundo - ou seja, observação direta, comunicação direta com as demais pessoas e a tentativa de explicação empírica dos fenômenos do mundo (MAVANGA apud MATAVEL, 2010).

Consequentemente, este trabalho é a descrição de uma sequência didática interdisciplinar, com os objetivos de valorizar a Agricultura familiar no ambiente escolar, perceber os conteúdos programáticos inseridos neste assunto, como a fotossíntese e sua importância para a vida dos seres vivos e promover a discussão da produção de alimentos do estado do Rio de Janeiro.

\section{METODOLOGIA}

A escola onde o projeto se desenvolveu é da esfera municipal do Rio de Janeiro, em área urbana, atendendo a alunos de comunidades não-pacificadas. Essas comunidades apresentam episódios de violência - ao ponto de a escola ser obrigada a fechar as portas por questão de segurança da comunidade escolar - e muitos alunos são assistidos pelos programas assistenciais governamentais, configurando uma escola que atende a classes média baixa e baixa. 
Os alunos participantes compõem duas turmas de $7^{\circ}$ ano do Ensino Fundamental (EF), com idades entre 12 e 14 anos e as atividades se desenvolveram no segundo bimestre letivo de 2014, compreendendo os meses de maio-junho-julho.

O envolvimento inicial na escola se deu a partir de uma professora que participou de uma palestra promovida pela Secretaria Municipal de Educação da cidade do Rio de Janeiro e, atuando como um agente multiplicador, reverberou este assunto com os demais colegas em uma reunião pedagógica.

Assim, os professores conversaram entre si sobre como trabalhar de uma forma contextualizada. Ficou decidida a adoção da Metodologia de Projetos, o que significa que a aprendizagem acontece com os conteúdos que aparecem à medida que o projeto se desenvolve.

Basicamente, esta metodologia pode ser dividida em três etapas: a problematização, o desenvolvimento e a síntese (BARBOSA, GONTIJO e SANTOS, 2003). A problematização é o momento em que o tema é proposto ou discutido com o grupo; o importante é que os alunos se sintam motivados a estudar tal tema; o desenvolvimento é a fase que demanda tempo para os alunos se planejarem e organizarem, realizando atividades com os objetivos a serem alcançados; finalmente, ocorre a síntese com a sistematização do que foi pesquisado. A avaliação do projeto, ainda de acordo com Barbosa, Gontijo e Santos (op. cit., 2003, p.8), "é desenvolvida ao longo de todo processo, buscando verificar a capacidade do aluno de resolver uma situação problemática real, dando o enfoque para a mobilização e a articulação dos recursos.”

\section{DESENVOLVIMENTO}

Inicialmente, foi realizada uma pesquisa oral com os alunos das turmas envolvidas em que se perguntava: "De onde vem o alimento que você come?" e, no total das respostas, surgiram opiniões semelhantes, como: “vem da fazenda", "vem do campo" e "vem do interior”. A professora pediu a descrição do que eles falavam e escrevia no quadro. Tipicamente, foram descritas situações de um latifúndio, como "uma plantação grande”, “um campo verde cheio de plantas iguais...tudo de milho, tudo de arroz..." e "um morro com bois". Ou seja, percebeu-se o completo desconhecimento de que a maior parte da refeição é oriunda do pequeno agricultor. Esse resultado foi passado para os demais docentes e a partir daqui, o percurso metodológico continuou sendo traçado.

Ocorreu, portanto, esta mobilização inicial sobre uma reflexão da origem dos alimentos da escola e da mesa de cada aluno e, para dinamizar, as turmas foram divididas em grupos menores de alunos e cada grupo ficou responsável pela pesquisa em um tema, a partir de duas perguntas-problema: a primeira "Você sabe de onde vem o alimento que você come?” e a segunda, “Como os alimentos têm ver com a saúde?”. A primeira pergunta ficou sob a responsabilidade dos professores de Geografia e de Matemática, e a segunda, ficou sob a responsabilidade da professora de Ciências. Assim, por interesse, houve grupos para pesquisar os temas de Ciências, outros grupos pesquisaram os temas em Geografia e outros pesquisaram os temas em Matemática, conforme o quadro abaixo (QUADRO 1):

\section{Quadro 1 - Temas para pesquisa}

\begin{tabular}{|l|l|}
\hline $\begin{array}{l}\text { Geografia e Matemática - “Você sabe de onde vem o } \\
\text { alimento que você come?” }\end{array}$ & Ciências - “Como os alimentos têm ver com a saúde?” \\
\hline - Agricultura Familiar; & - Fotossíntese: “a luz vira comida”; \\
- Produção agropecuária do estado do Rio de Janeiro; & - Alimentos e saúde; \\
- Calendário sazonal dos produtos agrícolas. & $\begin{array}{l}\text { - Pirâmide Alimentar; } \\
\text { - Conservação dos alimentos. }\end{array}$ \\
\hline
\end{tabular}


Posteriormente, cada grupo apresentou seus resultados sob a forma de seminários com a confecção de cartazes e/ou apresentação em slides.

Os alunos pesquisaram utilizando fontes impressas - jornais, revista e o livro didático - e também a internet, utilizando a Sala de Informática da escola; cada professor destinou tempos de aulas semanais para que esta pesquisa acontecesse.

Cada professor - de Ciências, Geografia e de Matemática - estudou e compartilhou as competências que foram adaptadas de documentos oficiais (INEP, 2011) a serem desenvolvidas a partir de conteúdos abordados no projeto “Agricultura familiar”, como pode ser visualizado no quadro 2:

\section{Quadro 2 - Competências}

\begin{tabular}{|c|c|c|}
\hline Área de conhecimento & Competências & Conteúdos curriculares \\
\hline Ciências & $\begin{array}{l}\text { - Compreender a natureza como um sistema dinâmico e o } \\
\text { ser humano, em sociedade, como um de seus agentes de } \\
\text { transformação. } \\
\text { - Relacionar saúde com hábitos alimentares e atividade física. } \\
\text { - Relacionar transferência de energia e ciclo de matéria a } \\
\text { diferentes processos (alimentação e fotossíntese). }\end{array}$ & $\begin{array}{l}\text { - Fotossíntese } \\
\text { - Alimentação saudável } \\
\text { - Pirâmide alimentar } \\
\text { - Conservação dos alimentos } \\
\text { - Elaboração de uma horta } \\
\text { vertical } \\
\end{array}$ \\
\hline Geografia & $\begin{array}{l}\text { - Reconhecer a formação e a organização do espaço geográfico } \\
\text { a partir das transformações ocorridas no campo e na cidade e } \\
\text { analisar interações entre sociedade e natureza na organização do } \\
\text { espaço histórico e geográfico, envolvendo a cidade e o campo. }\end{array}$ & $\begin{array}{l}\text { - Elaboração e interpretação } \\
\text { de mapas de produtos } \\
\text { agropecuários do estado do Rio } \\
\text { de Janeiro } \\
\end{array}$ \\
\hline Matemática & $\begin{array}{l}\text { - Avaliar propostas de intervenção na realidade, utilizando cálculos } \\
\text { de porcentagem e utilizando conhecimentos numéricos. }\end{array}$ & $\begin{array}{l}\text { - Numeral } \\
\text { - Interpretação de gráficos } \\
\text { - Porcentagem } \\
\text { - Resolução de problemas }\end{array}$ \\
\hline
\end{tabular}

Fonte: dos autores.

Todos os grupos demonstraram vontade em cumprir seus objetivos de pesquisa e houve apresentação de cartazes, desenhos e vídeos; um grupo sugeriu a criação de uma horta na escola - eles pesquisaram diferentes tipos e os recursos necessários. As turmas se engajaram na ideia e todos se envolveram na elaboração da primeira horta vertical da escola.

Foi marcada uma data para culminância com a apresentação das atividades produzidas pelos alunos por meio de uma exposição na escola (Figura 1):

\section{Figura 1 - Culminância do Projeto}

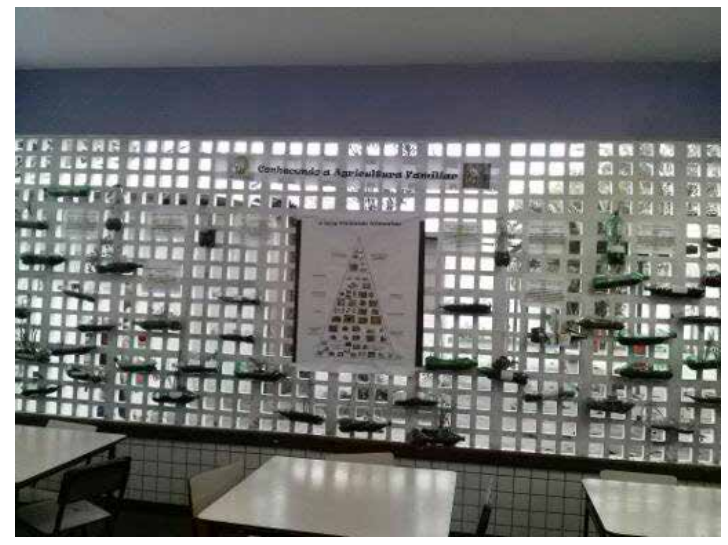

Fonte: Arquivo pessoal, 2014 


\section{RESULTADOS E DISCUSSÃO}

O resultado da pesquisa inicial sobre a origem dos alimentos com os alunos - o desconhecimento da importância da Agricultura Familiar como fonte primária de alimento - confirmou o que era esperado entre a equipe docente, pois até a mesma também desconhecia a participação tão efetiva e sólida no abastecimento dos produtos agropecuários à mesa do brasileiro. Tal fato pode ser reforçado pela leitura exploratória dos livros didáticos de Ciências e de Geografia do Ensino Fundamental adotados pela escola pesquisa, que não demonstram esse tipo de Agricultura e nem sua expressiva participação.

Quanto à adoção da Metodologia de Projetos, a dificuldade foi além do seu entendimento, mas a sua implantação e execução, pois a escola é submetida a um currículo que, em muitos momentos, não era correspondente ao que era pesquisado e encontrado pelos alunos no próprio projeto. Essa dificuldade foi superada à medida que os professores, sabiamente, administraram seus tempos letivos para cumprir o momento "do projeto" e o momento "curricular", para que fosse cumprida grade curricular já programada anteriormente por documentos oficiais da Secretaria Municipal de Educação do Rio de Janeiro; muitas vezes, foi necessário um esforço pedagógico dobre para que ambos os momentos fossem cumpridos.

Outra pontuação a respeito da Metodologia de Projetos é a autonomia que o aluno ou o grupo de alunos precisa desenvolver para que o projeto aconteça; em muitas situações, foi perceptível a postura ainda passiva do aluno, em esperar que o professor fale o que deva ser executado por ele. O projeto possibilita esta saída da zona de conforto, tanto pelo professor - que deixa de ser o mandatário da atividade escolar - quanto pelo aluno - que deixa de ser apenas o executor da atividade. A Metodologia de Projetos, ao proporcionar o fazer nas mãos dos alunos, despertou em muitos, o caráter de liderança e de organização. Também foram observadas atitudes de trabalho em equipe, com todas as nuances de negociação que acontece em trabalhos - o diálogo, o respeito à opinião do outro e o exercício de escutar. Também foram registrados momentos em que foi necessária a intervenção do professor para evitar episódios de violência em sala, ajudando os alunos a aprenderem a ouvir opiniões diferentes e respeitar. Foi um exercício de convívio social que a escola proporcionou na vivência do dia a dia.

As idas para a Sala de Informática foram momentos de motivação em todos os alunos, que se demonstraram ativos, conhecendo este suporte tecnológico e manejando sem dificuldades. Se, a princípio, a empolgação levava à uma desorganização, ao final do projeto, a postura da maioria dos alunos demonstrou mais foco para pesquisar o que realmente era necessário.

\section{CONSIDERAÇÕES FINAIS}

O envolvimento da comunidade escolar - professores, alunos, pais, coordenação pedagógica e equipe diretiva - foi fundamental, cada um colaborando para o início, meio e fim do projeto, em suas devidas esferas: professores e alunos na frente do projeto com o caminhar de toda a jornada, pais, para a compra do material necessário e a coordenação pedagógica e direção, para a cessão do espaço físico e a adequação dos horários e currículos.

O Projeto sobre a Agricultura Familiar desenvolveu estratégias que motivou os alunos à participação da aula, por meio de atividades diferenciadas que os levaram à tomada de posturas cognitivas, auxiliando-os a conhecer os conceitos científicos relacionados ao tema e também ao exercício de posturas sociais, ao proporcionar momentos de diálogo e de negociações durante o percurso pedagógico.

Este projeto também permitiu a reflexão e discussão da equipe de docentes que abraçou o projeto, onde efetivamente, na medida do possível, ocorreu a interdisciplinaridade do tema, proporcionando aos alunos a percepção da existência dos diversos conteúdos programáticos em um assunto que ainda não se discute na escola - a importância da Agricultura Familiar para a economia, para o abastecimento da mesa do brasileiro e para a conservação do ambiente natural. 


\section{REFERÊNCIAS BIBLIOGRÁFICAS}

BARBOSA, E. F.; GONTIJO, A. F.; SANTOS, F. F. Inovações pedagógicas em educação profissional: uma experiência de utilização do método de projetos na formação de competências. Educ. Tecnol., Belo Horizonte, v. 8, n. 2, p.06-13, jul./dez. 2003.

INEP. Ministério da Educação e Instituto Nacional de Estudos e Pesquisas Educacionais Anísio Teixeira. Matriz de competências. Disponível em: <http://portal.inep.gov.br/web/encceja/matriz-de-competencias $>$. Acesso em: 05 set. 2015.

FAO. 2014: Ano Internacional da Agricultura Familiar. Disponível em: < http://www.fao.org/familyfarming-2014/pt/>. Acesso em: 05 set. 2015.

FREIRE, P. Pedagogia da autonomia. Saberes necessários à prática docente. $4^{\mathrm{a}}$ ed. São Paulo: Paz e Terra, 1997.

GUILHOTO, J. J. M.; ICHIARA, S. M.; SILVEIRA, F. G.; DINIZ, B. P. C.; AZZONI, C. R.; MOREIRA, G. R.C. A importância da agricultura familiar no Brasil e em seus estados, 2007. Disponível: $<$ https://www. researchgate.net/publication/4731981>. Acesso em: 02 set. 2015.

MATAVEL, A. A. A influência das concepções alternativas na Aprendizagem de Mecânica: $O$ caso da Escola Secundária Joaquim Chissano. 2010. 60f. Monografia - Departamento de Física, Universidade Pedagógica, Xai-Xai, Moçambique, 2010. Disponível em: <https://www.academia.edu/10863812>. Acesso em: 08 set. 2015.

SAVIANI, D. Educação: do senso comum à consciência filosófica. 17. ed. revista. Campinas, SP: Autores Associados, 2007.

SPAROVEK, G.; FREITAS, F. L. M; MAULE, R. F. e MARTINS, S. P. Análise territorial e políticas para o desenvolvimento agrário. Brasília : Ministério do Desenvolvimento Agrário, 2013. Disponível em: <http://www.mda.gov.br/sitemda/sites/sitemda/files/user_arquivos_64/pageflip-4204229-487363-lt_Anlise_ territorial_e_-5306656.pdf $>$ Acesso em: 05 set. 2015.

VYGOTSKY, L. S. A formação social da mente: o desenvolvimento dos processos psicológicos superiores. Michael Cole et al (orgs.); tradução de José Cipollo Neto, Luís Silveira Menna Barreto e Solange Castro Afeche. $7^{a}$ Ed. São Paulo: Martins Fontes, 2007. 